\title{
MEMÓRIAS QUE INSTITUÍRAM A SANARE - REVISTA DE POLÍTICAS PÚBLICAS
}

Nesse ano de 2019, a SANARE - Revista de Políticas Públicas alcança seus 20 anos de história. Resgatála e recontá-la induz reconhecer e retratar o cotidiano dos serviços que se revestiam de novidades e lutas para a implantação e consolidação do Programa Saúde da Família em Sobral-CE. Comecemos, então!

0 Programa Saúde da Família nasce, em dezembro de 1993, a partir de experiências municipais que já estavam em andamento no País. Surge como uma proposta ousada para a reestruturação do sistema de saúde, organizando a atenção primária e substituindo os modelos tradicionais existentes ${ }^{1}$.

De tal modo, avanços foram acontecendo em diversos cenários do Brasil. Em Sobral-CE, até o ano de 1996, o modelo de saúde ainda era centrado na doença e com uma característica de gestão municipal com poucas formulações e execuções de políticas públicas, o que se manifestava nos diversos setores, mas era, acentuadamente, mais identificado na saúde. Assim, quase toda a rede de saúde era dotada de serviços assistenciais vinculados a entidades filantrópicas, privadas e a governo estadual. Até os serviços ambulatoriais de Atenção Básica estavam centralizados no hospital².

Movimentos foram tencionados para a implantação do Saúde da Família em Sobral-CE. Em 1997, elaborou-se um Plano Municipal de Saúde que teve o Programa Saúde da Família como modelo de Atenção Básica do município ${ }^{2}$. Dentre as estratégias de fortalecimento desse novo modelo, em 1999, foi criado o Programa de Residência Multiprofissional em Saúde da Família de Sobral ${ }^{3}$, tendo até o ano de 2018 concluído 15 turmas, com 398 egressos.

As provocações e problematizações tencionadas pelo referido Programa de Residência, pioneiro no Brasil, demandavam estratégias de visibilidade de suas ações exitosas, e que pudessem estimular novas formas de fazer no Saúde da Família, como novo orientador da Atenção Básica brasileira. Com tal intencionalidade, cria-se, no mesmo ano (1999), a então SANARE - Revista Sobralense de Políticas Públicas, de cunho estritamente local, com 11 artigos temáticos sobre o Saúde da Família e o seu processo de implantação no município.

Até seu último número (n.1, 2019), a SANARE - Revista de Políticas Públicas conta com 33 números distribuídos em 18 volumes, publicizando experiências e resultados de pesquisas em 438 artigos, os quais versam sobre variados temas envolvendo a Saúde Coletiva em âmbito local e nacional.

Convidamos, assim, à leitura dos artigos que compõem o n.2, 2019, da SANARE - Revista de Políticas 
Públicas que dialogam sobre importantes questões que perpassam o contexto da Saúde Coletiva no Brasil e que fomentam reflexões estratégicas para o fortalecimento de cotidianos de trabalho vivos e implicados com a melhoria da saúde brasileira.

Ademais, incitamos que leiam os números anteriores, de modo a visualizarem os retratos históricos de uma iniciativa local de publicização de experiências, mas que vem se tornando em uma estratégia potente para divulgar problematizações sobre os diversos contextos e questões que envolvem a saúde.

Desejamos a todos uma instigante leitura!

Profa. Dra. Maria Socorro de Araújo Dias

Editora Chefe da SANARE - Revista de Políticas Públicas

Diretora da Escola de Saúde Pública Visconde de Saboia

Profa. Me. Maria da Conceição Coelho Brito

Editora Assistente da SANARE - Revista de Políticas Públicas

Assistente de Pesquisa da Escola de Saúde Pública Visconde de Saboia

\section{REFERÊNCIAS}

1. Ministério da Saúde. Secretaria de Atenção à Saúde. Departamento de Atenção Básica. Memórias da saúde da família no Brasil / Ministério da Saúde, Secretaria de Atenção à Saúde, Departamento de Atenção Básica. Brasília: Ministério da Saúde; 2010.

2. Andrade LOM, Martins Júnior T. Saúde da Família: construindo um novo modelo - a experiência de Sobral. $1999 ; 1(1): 1-11$

3. Andrade LOM, Goya N, Martins Júnior T, Barreto ICHC. Escola de Formação em Saúde da Família Visconde de Saboia-Sobral (CE): uma resposta municipal para a Educação permanente no SUS. Divulg. Saúde Debate. $2004 ; 30: 15-25$. 